\title{
Composición de tierras y tendencias de poblamiento hispano en la franja costera. Culiacán y Chiametla, siglos XVII y XVIII
}

\section{GILBERTO LÓ PEZCASTILLO \\ Culiacán: INAH, Centro InAH Sinaloa-H. Ayuntamiento de Culiacán, Instituto Municipal de Cultura de Culiacán 2014 | ISBN 9786078039500 | 195 pp.}

ESTHER PADILLA CALDERÓN El Colegio de Sonora, Hermosillo, México

ilberto López Castillo se ha interesado por comprender los procesos de I contacto entre sociedades amerindias y europeas o novohispanas. En el libro que nos ocupa articula las composiciones de tierras y los procesos de poblamiento para acercarse a la reconstrucción histórica de la conformación y evolución social de las alcaldías de Culiacán y Chiametla, situadas la primera en la región central del actual estado de Sinaloa y la segunda, en su región sur. Sinaloa constituye una significativa franja territorial, en gran medida costera, del noroeste de México. Dichas provincias novohispanas estuvieron adscritas a distintas jurisdicciones: Chiametla vio cambiar su adscripción de Nueva Galicia a Nueva Vizcaya, mientras que Culiacán permaneció bajo el mando de Nueva Galicia, hasta el surgimiento de la gobernación de Sonora y Sinaloa, en 1732.

Aunque el autor reconoce la composición de tierras como institución novohispana, su intención no ha sido realizar un estudio institucional sino comprender la lógica del desarrollo de las composiciones en las alcaldías mencionadas, con el objetivo no explícito de avanzar sobre el conocimiento de los procesos 
histórico-sociales del poblamiento del actual Sinaloa los que, al decir de este y otros autores - de distinto sello disciplinar-, son procesos inacabados, que al ser estudiados en la larga duración permiten advertir cómo se reconfiguran los territorios sociales. López Castillo reconoce en el desarrollo de las composiciones de tierras la participación de numerosos actores; entre estos identifica particularmente al juez de tierras como figura protagónica del devenir de esta institución, cuya labor dejó también para la historia importantes testimonios, útiles en la construcción de una historia social de las composiciones y también del poblamiento, como queda demostrado.

El autor aclara que se ha acercado al tema del poblamiento para avanzar en el conocimiento del "proceso de ocupación del espacio", "de apropiación del suelo” (López 20). Así, por un lado, estudia el proceso de ocupación del territorio por parte de población indígena, y por el otro, de población hispana, y la interacción entre ambos, lo que le permite identificar la conformación de jurisdicciones y los cambios en estas, así como acercarse al desenvolvimiento del proceso demográfico. Identifica cuatro fases del poblamiento, que más adelante comentaremos, y cierra su periodo de estudio en 1790 , ańo que enmarca el "punto más bajo" (López 27) en el arribo de nuevos pobladores a tierras realengas y en el que se establecen con más claridad nuevos canales institucionales bajo el control de la intendencia de Arizpe para la definición de composiciones de tierras.

El libro versa entonces sobre dos grandes temas interrelacionados: composiciones de tierras y poblamiento. Respecto del primero, como sabemos, el autor que más ha contribuido a su conocimiento es Francisco de Solano (Cedulario; "El juez"; “Tierra”), aunque para la región norte de la Nueva España destaca el trabajo de Salvador Álvarez ("Tendencias"), el cual evidencia la relación entre procesos de poblamiento y formación de grandes unidades productivas. Rosa Alicia de la Torre (Cambios) y López Castillo emplean las composiciones de tierras en el mismo sentido: como fuente para acercarse al conocimiento de la apropiación del territorio y los procesos de poblamiento. En el último tema destacan los aportes de Torales Pacheco ("A note"; Tierras) sobre Cholula. Respecto de Chiametla y Culiacán, López Castillo señala que los ranchos, puestos, estancias y haciendas fueron con frecuencia objeto de una composición, y que esta figura sirvió para legitimar "en su posesión a la población hispana", sobre todo de tierras que pertenecían originalmente a los indígenas y que habían quedado despobladas por el proceso de baja demográfica, o que no estaban siendo usufructuadas por los pobladores originarios quienes, a pesar de la existencia de leyes que protegían sus derechos, vieron afectado su territorio con el proceso 
de expansión ganadera. Al respecto, el trabajo de Cinthya Radding (Wandering) sobre el actual Sonora es central. López Castillo observa que, en el espacio que ha estudiado, la composición de tierras sirvió "para legitimar diversas anomalías en el sistema de propiedad territorial" (43). En lo relativo a periodos similares, se sabe que en otras zonas de México, como Oaxaca y Guadalajara, los indígenas lograron sostener durante largo tiempo sus derechos sobre la tierra (Taylor, Landlord; Van Young, La ciudad).

La ocupación del suelo, su denuncio, la mensura son en sí mismos procesos y a la vez etapas constituyentes de un proceso de composición de tierras, previas por supuesto a la expedición del título y a la real confirmación. Aunque indudablemente son contextos harto diferentes, no es difícil - y creo que tampoco vano- hacer analogías con procesos agrarios de periodos posteriores, aun con los acaecidos en el siglo xx, e identificar paralelismos históricos entre procedimientos y actores, individuales o colectivos, involucrados. Existen relaciones, a pesar de tratarse de hechos tan distantes en el tiempo, a grado tal que, por ejemplo, las famosas mojoneras de cal y canto levantadas en el siglo Xvir tras la indicación de algún juez de tierras continuaron siendo determinantes en tareas de delimitación de predios a cargo de ingenieros auxiliares de la Comisión Nacional Agraria, en la primera mitad del siglo xx. Es importante advertir la continuidad — transcurrida en la larga duración — de situaciones relativas a la apropiación territorial y la constitución de la propiedad sobre el suelo.

Dar seguimiento a las etapas de composición permite a López Castillo, en el caso de las provincias de Culiacán y Chiametla, develar su lento poblamiento por hispanos y descubrir la efectividad de la composición como forma de apropiación del territorio, incluso en sitios tan alejados del centro de poder novohispano como las jurisdicciones objeto de estudio. Componer implicaba diversas gestiones ante variadas instancias, y aunque hubo más de una instrucción real relativa a este proceso, la real cédula de 1754 constituye el referente legal más significativo del periodo estudiado, pues fue un detonante para la composición y para la confirmación de la propiedad de las tierras mediante títulos de merced, que también podían obtenerse por adjudicación. La composición de tierras cumplió dos funciones centrales: "poner en orden la ocupación del suelo" acaecida de "forma arbitraria” y captar "ingresos reales”. En síntesis, tenía un carácter catastral y recaudatorio, sobre el que recientemente Sergio Eduardo Carrera ha hecho una excelente contribución ("Las composiciones"), centrada en dos jurisdicciones de la Huasteca. 
El autor del libro que nos ocupa muestra que tanto jueces como pobladores se esforzaron por culminar los procesos de legalización de posesiones, y señala una diferencia importante entre las provincias de Chiametla y Culiacán: en el siglo XVI esta última no tenía visos de ser un sitio con "perspectiva de hacer grandes negocios para los funcionarios" de la Corona, mientras que la primera era tierra prometedora desde entonces, pues ahí se desarrollaron importantes proyectos mineros y su bonanza se convirtió en incentivo del poblamiento hispano, que fue lento y se presentó con altibajos debido a los vaivenes de la minería. El clima cálido y húmedo, propio de las costas de estas latitudes, así como la presencia de ponzońosos e incómodos dípteros como los mosquitos y los jejenes, supuso problemas de adaptación para la población novohispana, en áreas en las cuales los nativos habían desarrollado la agricultura, la pesca y la explotación de las salinas, y que luego se convertirían en zonas preferidas para la reproducción de ganado. Como señaló Salvador Álvarez, la minería fue muy importante en el desarrollo de Chiametla (El indio i6), en tanto que la pesca y la ganadería tuvieron importancia en ambas provincias.

En Chiametla las alcaldías se formaron y extinguieron de acuerdo con los ritmos del desarrollo minero, mientras en el área de Culiacán su existencia fue más estable, debido a que la villa de San Miguel fue sede permanente de la Alcaldía Mayor de la provincia. La primera de las cuatro fases identificadas por el autor con respecto al proceso de poblamiento de Chiametla y Culiacán, durante los siglos XVI al XVIII, inicia con la llegada de Nuño de Guzmán a la región en 1530 y concluye con el siglo; en la segunda, que inicia en $\mathrm{r} 600$ y culmina en 1670 , el poblamiento hispano es lento y escaso y la población nativa disminuye; en la tercera, la cual inicia en I67I y concluye en I760, se presenta un "vigoroso impulso poblador"; y en la cuarta fase ocurre el poblamiento de sitios hasta entonces deshabitados y se advierte la culminación del poblamiento de tierras realengas de buena calidad. Por lo tanto, en la primera mitad del XVIII coinciden el vigoroso avance del poblamiento y el ritmo dinámico de las composiciones de tierras con una fuerte presión sobre las tierras de los nativos, y tiene lugar la concentración de la tierra en pocas manos, sobre todo en Chiametla. Respecto de la segunda mitad del siglo, se advierten cambios sustantivos a nivel del noroeste novohispano cuando el poblamiento es significativo y se lo relaciona con la expulsión de los jesuitas. Sin embargo, en Chiametla y Culiacán — sitios iniciales de poblamiento hispano en el noroeste de la Nueva Españael establecimiento de nuevas unidades de composición disminuye notablemente y los sitios donde se alojan nuevos pobladores no son localizaciones nuevas. 
En el "balance final" del texto se nos advierte del desfase de un siglo con relación a otras zonas del Imperio español respecto de la instauración de las alcaldías y la aparición de los jueces de tierras, por lo que las propiedades de quienes se establecían en la región eran sancionadas por autoridades locales, sin llegar a ser propiamente composiciones. Por ello, debieron buscar este reconocimiento posteriormente. Los ranchos y las estancias, que se situaron sobre todo en las cercanías de las villas y los reales mineros, pero también en el litoral y en la serranía, constituyeron unidades típicas del poblamiento de la costa. Es un libro interesante, que responde preguntas importantes relacionadas con el desarrollo del poblamiento en un área significativa del actual estado de Sinaloa; además, plantea preguntas y favorece el surgimiento de otras. El autor considera que la inclusión de nuevas fuentes para el estudio del poblamiento de la región enriquecería el rico marco empírico y explicativo sobre el proceso de poblamiento, sobre el que ha avanzado a partir del uso de la información que proveen las composiciones de tierras.

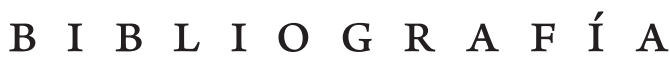

Álvarez, Salvador. "Tendencias regionales de la propiedad territorial en el norte de la Nueva España: siglos xviı y xvıII". Actas del Segundo Congreso Nacional de Historia Comparada. Ciudad Juárez, Chihuahua, México: Universidad Autónoma de Ciudad Juárez, I99I, pp. I4I-I79.

---. El indio y la sociedad colonial norteña, siglos XVI-XVIII. Durango: Instituto de Investigaciones Históricas; Universidad Juárez del Estado de Durango-El Colegio de Michoacán A. C., 2009.

Carrera Quezada, Sergio Eduardo. "Las composiciones de tierras en los pueblos de indios en dos jurisdicciones coloniales de la Huasteca, I692-1720". Estudios de Historia Novohispana, n. ${ }^{\circ}$ 52, 2015, pp. 29-50. Web. 8 de enero del 2016.

De la Torre, Rosa Alicia. Cambios demográficos y de propiedad territorial en la provincia de Ávalos. Guadalajara: Universidad de Guadalajara, 2012.

De Solano, Francisco. "Tierra, comercio y sociedad, un análisis de la estructura social agraria centroamericana durante el siglo xviII". Revista de Indias, n. ${ }^{\circ} 3 \mathrm{I}, \mathrm{I} 97 \mathrm{I}$, pp. $3 \mathrm{II}-365$. 
---. "El juez de tierras y la Superintendencia del Beneficio y Composición de Tierras". Anuario Histórico Jurídico Ecuatoriano. Separata vi, I98o, pp. 347-36o.

---. Cedulario de tierras. Compilación de legislación agraria colonial (1497-1820). México D. F.: Instituto de Investigaciones Jurídicas, Universidad Nacional Autónoma de México, 1984.

Radding, Cynthia. Wandering Peoples. Colonialism, Ethnic Spaces, and Ecological Frontiers in Northwestern Mexico, I700-1800. Durham: Duke University Press, 1997.

Taylor, William. Landlord and Peasant in Colonial Oaxaca. California: Stanford University Press, 1972.

Torales Pacheco, María Cristina. "A Note on the Composiciones de Tierra in the Jurisdiction of Cholula, Puebla (1591-1757)". The Indian Community of Colonial Mexico. Fifteen Essays on Land Tenure, Corporate Organizations, Ideology and Village Politics, editado por A. Ouweneel y S. Miller. Ámsterdam: Centro de Estudios y Documentación Latinoamericanos, 1990, pp. 87-Ior.

---. Tierras de indios, tierras de españoles. Confirmación y composición de tierras y aguas en la jurisdicción de Cholula (siglos XVI-XVIII). México D. F.: Universidad Iberoamericana, 2005 .

Van Young, Eric. La ciudad y el campo en el siglo XVIII. La economía rural de la región de Guadalajara, I675-1820. México D. F.: Fondo de Cultura Económica, I989. 